\title{
Hereditary Isolated Glucocorticoid Deficiency Is Associated with Abnormalities of the Adrenocorticotropin Receptor Gene
}

\author{
Constantine Tsigos, * Keiko Arai, * Wellington Hung, ${ }^{\star}$ and George P. Chrousos * \\ *Developmental Endocrinology Branch, National Institute of Child Health and Human Development, Bethesda, Maryland \\ 20892; and ${ }^{\ddagger}$ Department of Pediatrics, Georgetown University School of Medicine, Washington, DC 20007
}

\begin{abstract}
Isolated glucocorticoid deficiency (IGD) is an autosomal recessive disorder characterized by progressive primary adrenal insufficiency, without mineralocorticoid deficiency. The cDNA and gene of the human ACTH receptor were recently cloned. The gene encodes a 297-amino acid protein that belongs to the $G$ protein-coupled superfamily of membrane receptors. We hypothesized that the ACTH receptor gene might be defective in IGD. To examine this, we studied its genomic structure by PCR and direct sequencing in a 5-yr-old proband with the disease, his parents, and grandparents. The proband was a compound heterozygote for two different point mutations, one in each allele: $(a)$ a substitution $(C \rightarrow T)$, also found in one allele of the mother and maternal grandmother, which introduced a premature stop codon (TGA) at position 201 of the protein; this mutant receptor lacks its entire carboxy-terminal third and, if expressed, should be unable to transduce the signal; and (b) a substitution $(C \rightarrow G)$, also found in one of the paternal alleles, which changed neutral serine ${ }^{120}$ in the apolar third transmembrane domain of the receptor to a positively charged arginine, probably disrupting the ligand-binding site. Standard ovine corticotropin releasing hormone (oCRH) test in the heterozygote parents and maternal grandmother revealed exaggerated and prolonged ACTH responses, suggestive of subclinical resistance to ACTH. We conclude that IGD in this family appears to be due to defects of the ACTH receptor gene. The oCRH test appears to be useful in ascertaining heterozygosity in this syndrome. (J. Clin. Invest. 1993.92:2458-2461.) Key words: adrenal insufficiency $\bullet$ ACTH receptor $\bullet$ CRH test $• \mathrm{G}$ protein-coupled receptors
\end{abstract}

\section{Introduction}

Hereditary isolated glucocorticoid deficiency is a rare autosomal recessive disorder characterized by primary adrenal insufficiency without mineralocorticoid deficiency (1-3). Affected children usually have recurrent hypoglycemia, convulsions, or coma, which may result in death within the first 2 yr of life. Unless recognized and treated early, this condition may lead to chronic asthenia and failure to thrive. The disorder is occasionally associated with alacrima and achalasia of the esophagus, suggesting potential heterogeneity in its etiology $(4,5)$. Affected individuals have no cortisol or aldosterone responses to

Address correspondence to Dr. C. Tsigos, Developmental Endocrinology Branch, Building 10, Room 10N262, National Institutes of Health, 9000 Rockville Pike, Bethesda, MD 20892.

Received for publication 27 July 1993.

The Journal of Clinical Investigation, Inc.

Volume 92, November 1993, 2458-2461 exogenous ACTH but retain a normal aldosterone response to activation of the renin-angiotensin axis by salt restriction, orthostasis, and furosemide-induced diuresis (6-8). In keeping with the biochemical studies, in these patients the angiotensin II-dependent zonae fasciculata and reticularis are extremely atrophic, reduced to a narrow band of fibrous tissue, while the zona glomerulosa is relatively well preserved $(1,2,6)$. The generalized adrenal unresponsiveness to ACTH that underlies the pathogenesis of isolated glucocorticoid deficiency suggests that the defect responsible could be anywhere in the signaling cascade, from the membrane-bound $G$ protein-coupled ACTH receptor to the kinases stimulating steroidogenesis. A defect in the $G$ protein or adenylyl cyclase, both of which are ubiquitous molecules whose dysfunction would be expected to affect multiple organs, would be a rather unlikely explanation for the syndrome of ACTH resistance, which is limited to the adrenal cortex.

Recently, the human ACTH receptor gene was cloned and its sequence determined (9). It encodes a 297-amino acid protein, which together with the melanocyte-stimulating hormone receptors, constitute a class of $G$ protein-coupled receptors whose genes are intronless. To test the hypothesis that abnormalities of the ACTH receptor gene might lead to hereditary isolated glucocorticoid deficiency, we examined this gene in a boy with this condition, his parents, and grandparents. We used standard ovine corticotropin releasing factor $(\mathrm{oCRH})^{1}$ stimulation testing to ascertain subclinical ACTH resistance in asymptomatic members of the family found to be heterozygotes for defects of the ACTH receptor gene.

\section{Methods}

Patients. The pedigree studied is summarized in Fig. $1 \mathrm{~A}$. The proband, a 5-yr-old black boy, was born at full-term by vaginal delivery to healthy 21 -yr-old nonconsanguineous parents. Generalized hyperpigmentation was present from birth. He was in good health until 9 mo of age, when he was found in the morning to be unconscious and unresponsive to stimuli. He was taken to an emergency room and his blood glucose was $20 \mathrm{mg} / \mathrm{dl}$. He had a good response to intravenous glucose but no definitive diagnosis was made. The patient had another documented hypoglycemic episode at $12 \mathrm{mo}$ of age. He was seen by one of us (W. Hung) at 14 mo of age because of unresponsiveness and blood glucose of $25 \mathrm{mg} / \mathrm{dl}$. At this time, his serum cortisol was $<1 \mu \mathrm{g} / \mathrm{dl}$ and plasma ACTH was $426 \mathrm{pg} / \mathrm{ml}$ (normal, 9-52 pg/ml). Further workup revealed normal plasma renin activity and aldosterone concentration. There was no increase in serum cortisol levels after intravenous injection of ACTH 1-24. A diagnosis of isolated glucocorticoid deficiency was made and the patient has since been maintained on hydrocortisone replacement, on which he has had normal growth and intellectual development. The patient has no siblings, and his parents and

1. Abbreviation used in this paper: $\mathrm{OCRH}$, ovine corticotropin releasing hormone. 
grandparents have been healthy and have not had any symptoms or signs suggestive of adrenal dysfunction.

DNA preparation and analysis. Genomic DNA was prepared from whole blood from the proband, his parents, and three grandparents, and used as a template for amplification of the intronless ACTH receptor gene by the PCR. The following pair of flanking primers were used: sense 5'-GTCCAAGTAACATCCCCGCCTTAACCAC-3' and antisense 5'-GGATTCTAAAACCAGGGATCAGCCATTC-3'. Amplification was allowed for 30 cycles in a Gene Amp PCR system (9600; Perkin Elmer Cetus, Norwalk, CT). Except for the first and last, all cycles were $30 \mathrm{~s}$ at $98^{\circ} \mathrm{C}, 30 \mathrm{~s}$ at $55^{\circ} \mathrm{C}$, and $3 \mathrm{~min}$ at $73^{\circ} \mathrm{C}$, in a $100-\mu \mathrm{l}$ volume with Pyrococcus furiosus DNA polymerase (Stratagene, La Jolla, CA). In the first cycle, all temperature steps were $5 \mathrm{~min}$, while in the last cycle the extension step at $73^{\circ} \mathrm{C}$ was $15 \mathrm{~min}$. The PCR product was used to produce single-stranded DNA by asymmetric PCR, using either primer alone. This was carried out for 20 cycles in a $100-\mu 1$ volume, as described above. The amplified single-stranded DNA was purified by filtration through a millipore membrane and was directly sequenced by the dideoxy nucleotide chain termination method, as modified by Kadowaki et al. (10), using modified T7-DNA polymerase (Sequenase; United States Biochem. Corp., Cleveland, $\mathrm{OH}$ ) in the presence of ${ }^{35} \mathrm{~S}$-dATP. Inner primers that span the ACTH receptor domain were used for sequencing and the reaction products were run on $6 \%$ acrylamide gel.
oCRH stimulation testing. We performed a standard 3-h oCRH stimulation test in the obligate heterozygote parents of the proband and his carrier maternal grandmother in an attempt to detect any subclinical abnormalities of the hypothalamic-pituitary-adrenal axis that might be associated with their heterozygote status for the mutations identified. An intravenous catheter was inserted $1 \mathrm{~h}$ before the test in an antecubital vein. $\mathrm{OCRH}(1 \mu \mathrm{g} / \mathrm{kg})$ was given at $1900 \mathrm{~h}$ as an intravenous bolus injection and blood was drawn at $-15,0,5,15,30,60,90$, 120,150 , and $180 \mathrm{~min}$, as previously described (11). Plasma ACTH and cortisol were measured by previously described radioimmunoassays (11).

\section{Results}

Two different point mutations were identified in the genomic DNA of the ACTH receptor of the proband (Fig. 1). The first mutation was a substitution of cytosine by thymidine at the first position of codon 201, normally encoding arginine, introducing the stop codon TGA (Fig. $1 B$ ). The site of this mutation corresponds to the beginning of the third intracellular loop of the ACTH receptor protein. Thus, the mutant receptor lacks the entire carboxy-terminal third and retains only 3 of the 20

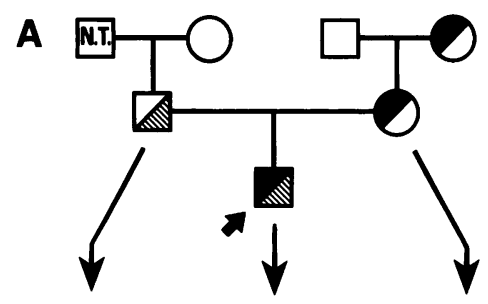

B 3rd cytosolic loop

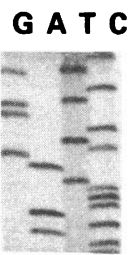

Normal

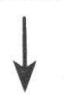

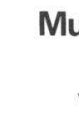
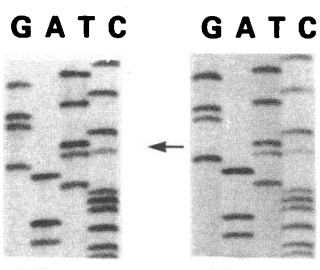

Mutant<smiles>C1CC2CCC3CC(C1)C23</smiles>

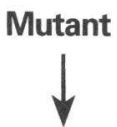

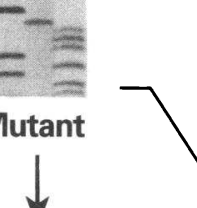

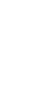$$
\text { (1) }
$$
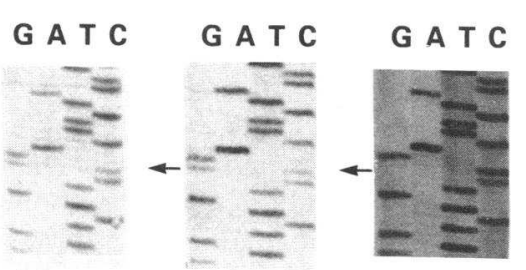

Mutant
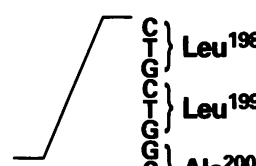
C) Ala200 G) Arg $\stackrel{201}{\longrightarrow}$ Stop C. Ser201 Á. His 202 Thro3

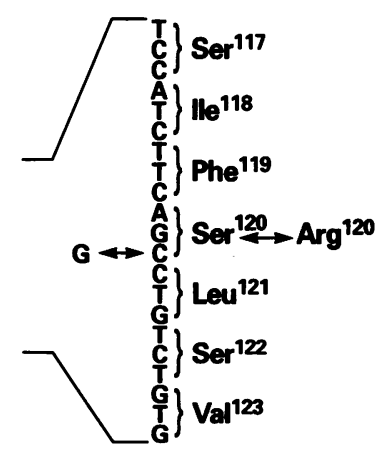

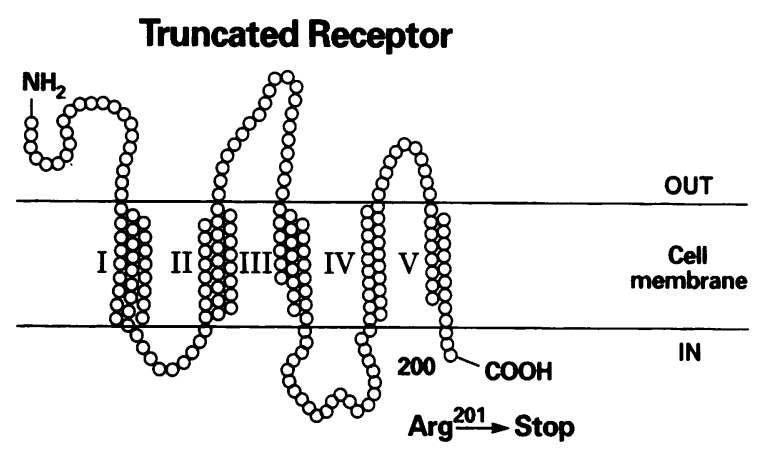

Normal Length Receptor

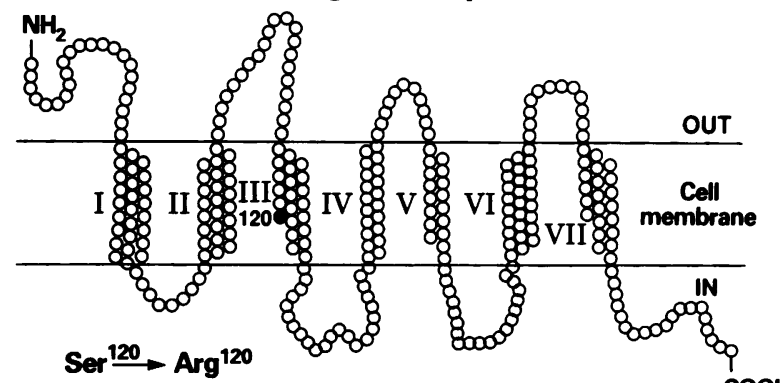

COOH

Figure 1. DNA sequencing of the ACTH receptor gene in the proband and his family. $(A)$ Family pedigree. The proband (small arrow) is a mixed heterozygote for a stop codon at position 201 (solid) and a nonconservative amino acid substitution from Ser to Arg at position 120 ( $h a t c h e d$ ). The stop codon mutation is also carried by his mother and maternal grandmother, and the nonconservative substitution by his father. $(B)$ DNA sequencing of the area of the gene carrying the stop codon within the third cytosolic loop, which results in the truncated ACTH receptor, is shown on the right. $(C)$ DNA sequencing of the area of the gene carrying the nonconservative substitution within transmembrane domain III, which results in an ACTH receptor carrying a basic Arg in this domain, is shown on the right. N.T., not tested. 
amino acids of the third intracellular loop. The second mutation was a substitution of cytocine by guanine at the third position of codon 120 causing a nonconservative amino acid substitution from serine to arginine (Fig. $1 C$ ). This mutation is in transmembrane domain III of the receptor.

Each of the mutations found in the proband were also present in his mother and father, who were, respectively, heterozygotes for the stop codon mutation and the nonconservative amino acid substitution (Fig. 1). The maternal grandmother was also a heterozygote for the stop codon mutation.

The oCRH stimulation test revealed abnormalities in all three heterozygote carriers determined by gene sequencing, with all of them having exaggerated and prolonged plasma ACTH responses to oCRH (Fig. 2). Plasma cortisol responses ranged between normal and slightly elevated.

\section{Discussion}

It appears that the combination of the two point mutations identified in each of the alleles of the ACTH receptor gene of the proband is the cause of his isolated glucocorticoid defi-
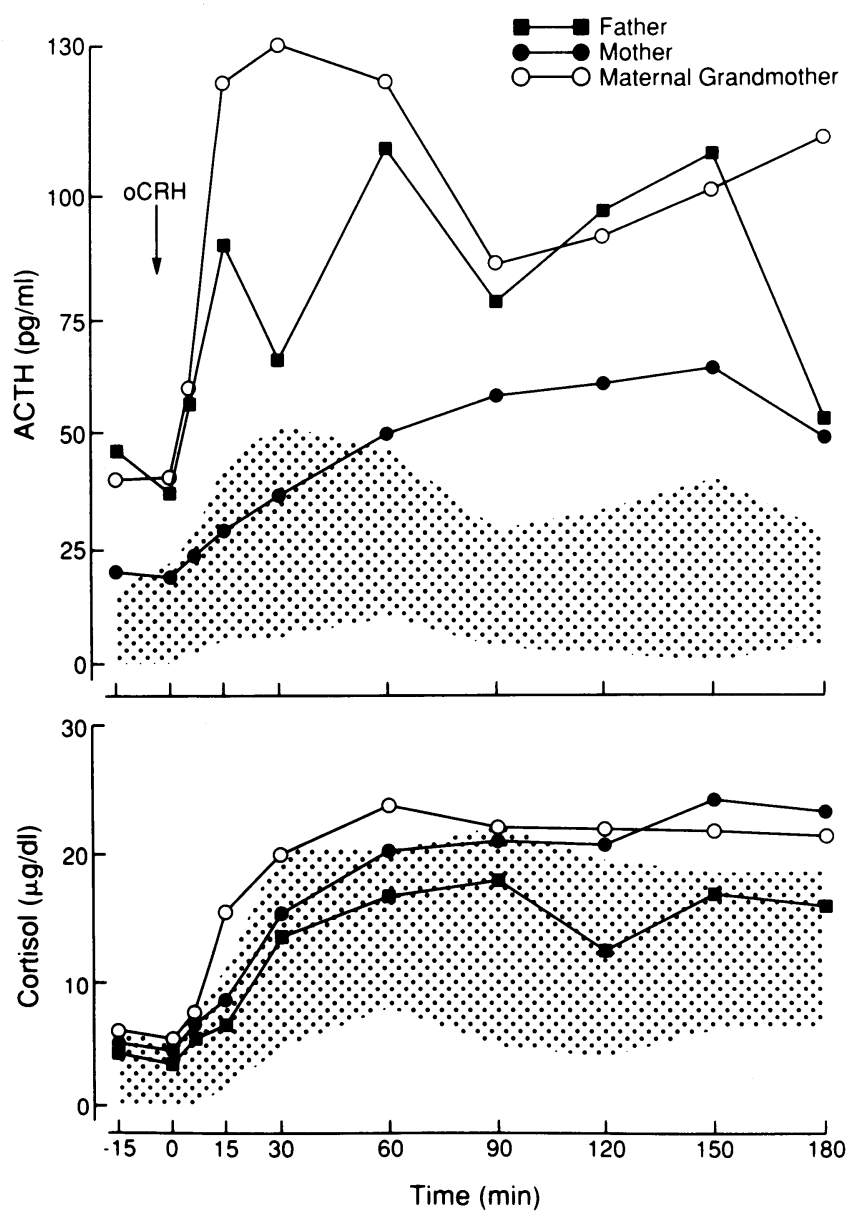

Figure 2. Plasma ACTH (top) and cortisol (bottom) responses to oCRH $(1 \mu \mathrm{g} / \mathrm{kg}$ i.v. $)$ in the carrier parents and maternal grandmother of the proband. All carriers had exaggerated and prolonged ACTH responses but normal or slightly elevated cortisol responses. Shaded areas represent the mean \pm 2 SD of normal controls. To convert values of ACTH to picomoles per liter and of cortisol to nanomoles per liter, multiply by 0.22 and 27.6 , respectively. ciency. The premature termination introduced by one of these mutations would eliminate a large part of the receptor molecule that interacts with the $G$ protein. The protein product of this mutant allele, if expressed, should be truncated and unable to transduce a signal. Recently, similar mutations, introducing stop codons in the third cytosolic loop of the vasopressin V2 receptor, were associated with vasopressin resistance and nephrogenic diabetes insipidus (12-14). Null mutations in the rhodopsin gene were also associated with rod photoreceptor dysfunction and autosomal recessive retinitis pigmentosa (15).

The nonconservative amino acid substitution introduced by the other mutation in transmembrane domain III of the ACTH receptor would also be expected to result in a dysfunctional receptor protein. $G$ protein-coupled receptors have several highly conserved, negatively charged aspartate residues within the apolar transmembrane domains II and III, which are apparently crucial in the formation of the ligand binding site of the receptor $(16,17)$. Substitution of such a highly conserved aspartate at the beginning of transmembrane domain III with asparagine caused a reduction in the affinity of mutant muscarinic and $\alpha 2$ - and $\beta 2$-adrenoreceptors in the order of 10,000 fold $(18,19)$. Even a conservative change of this aspartate residue to glutamate caused a 1,000-fold reduction in the binding affinity of the $\beta$-adrenoreceptor (19). The clinical importance of this region in receptor function is underscored by two recent reports of nephrogenic diabetes insipidus, in which the gene abnormality responsible for the disease was a point mutation in transmembrane domain III of the vasopressin V2 receptor ( 12 , 13). Thus, we believe that the substitution of the neutrally charged serine ${ }^{120}$ in the overall apolar transmembrane domain III by arginine might interfere with the formation of the ACTH-binding pocket, rendering the mutant receptor dysfunctional. By virtue of its position, this mutation might also interfere with the conformation of the second cytosolic loop of the receptor, which contributes to the $G$ protein binding site (20).

The inappropriately exaggerated and prolonged plasma ACTH responses to oCRH in the heterozygote parents and maternal grandmother of our patient suggest that heterozygosity for the mutations identified represents a carrier state characterized by subclinical resistance to ACTH. These findings provide in vivo evidence in support of a cause-effect relationship between the mutations identified and the isolated glucocorticoid deficiency in this family, and indicate that the oCRH test might be appropriate for ascertaining heterozygosity in other families with this syndrome. Interestingly, similar heterozygosity in kindrends with nephrogenic diabetes insipidus and retinitis pigmentosa results in subtle but detectable abnormalities in osmoregulation and retinal electrical activity, respectively $(14,15)$.

So far, there has been a single report of a different point mutation of the ACTH receptor gene in another kindred with hereditary isolated glucocorticoid deficiency (21). It is of note that the proband in this family was homozygotic for a conservative substitution of a serine by isoleucine in transmembrane domain II. No biochemical ascertainment of heterozygosity was attempted.

\section{Acknowledgments}

We thank Dr. Roger Cone (Vollum Institute, Portland, OR) for sending us the DNA sequence of the ACTH receptor and Dr. Nicholas Vamvakopoulos for his assistance in the early phases of this project. 


\section{References}

1. Shepard, T. H., B. H. Landing, and D. G. Mason. 1959. Familial Addison's disease. Case report of two sisters with corticoid deficiency unassociated with hypoaldosteronism. Am. J. Dis. Child. 97:154-162.

2. Migeon, C. J., F. M. Kenny, A. Kowarski, C. A. Snipes, J. S. Spaulding. J. W. Finkelstein, and R. M. Blizzard. 1968. The syndrome of congenital unresponsiveness to ACTH. Report of six cases. Pediatr. Res. 2:501-513.

3. Thistletwaite, D., J. A. B. Darling, R. Fraser, P. A. Mason, L. H. Rees, and R. A. Harkness. 1975. Familial glucocorticoid deficiency. Studies of diagnosis and pathogenesis. Arch. Dis. Child. 50:291-297.

4. Allgrove, J., G. S. Clayden, B. D. Grant, and J. C. Macaulay. 1978. Familial glucocorticoid deficiency with achalasia of the cardia and deficient tear production. Lancet. i:1284-1286.

5. Moore, P. S. J., R. M. Couch, Y. S. Perry, E. P. Shuckett, and J. S. D. Winter. 1991. Allgrove syndrome: an autosomal recessive syndrome of ACTH insensitivity, achalasia and alacrima. Clin. Endocrinol. 34:107-114.

6. Kelch, R. P., S. L. Kaplan, E. G. Biglieri, G. H. Daniels, C. J. Epstein, and M. M. Grumbach. 1972. Hereditary adrenocortical unresponsiveness to adrenocorticotropin hormone. J. Pediatr. 81:726-736.

7. Soltesz, G., M. J. Dillon, P. A. Jenkins, A. Moore, and A. Aynsley-Green. 1985. Isolated glucocorticoid deficiency: metabolic and endocrine studies in a 5-year-old boy. Eur. J. Pediatr. 143:297-300.

8. Spark, R. F., and J. R. Etzkorn. 1977. Absent aldosterone response to ACTH in familial glucocorticoid deficiency. $N$. Engl. J. Med. 297:917-920.

9. Mountjoy, K. G., L. S. Robbins, M. T. Mortrud, and R. D. Cone. 1992. The cloning of a family of genes that encode the melanocortin receptors. Science (Wash. DC). 257:1248-1251.

10. Kadowaki, T., H. Kadowaki, and S. I. Taylor. 1990. A nonsense mutation causing decreased levels of insulin receptor mRNA: detection by a simplified technique for direct sequencing of genomic DNA amplified by the polymerase chain reaction. Proc. Natl. Acad. Sci. USA. 87:658-663.

11. Schulte, H. M., G. P. Chrousos, E. H. Oldfield, P. W. Gold, G. B. Cutler, and D. L. Loriaux. 1985. Ovine corticotropin-releasing factor administration in normal men. Horm. Res. (Basel). 21:69-74.

12. Rosental, W., A. Seibold, A. Antaramian, M. Lonerga, M-F. Arthus, G. N. Hendy, M. Birnbaumer, and D. G. Bichet. 1992. Molecular identification of the gene responsible for congenital nephrogenic diabetes insipidus. Nature (Lond.). 359:233-235.

13. Pan, Y., A. Metzenberg, S. Das, B. Jing, and J. Gitschier. 1992. Mutations in the V2 vasopressin receptor gene are associated with X-linked nephrogenic diabetes insipidus. Nature Genetics. 2:103-106.

14. Merendino, Jr. J. J., A. M. Spiegel, J. D. Crawford, A. N. O'Carroll, M. J. Brownstein, and S. J. Lolait. 1993. Brief report: a mutation in the vasopressin V2-receptor gene in a kindred with X-linked nephrogenic diabetes insipidus. $N$. Engl. J. Med. 238:1538-1541.

15. Rosenfeld, P. J., G. S. Cowley, T. L. McGee, M. A. Sandberg, E. L. Berson, and T. P. Dryja. 1992. A null mutation in the rhodopsin gene causes rod photoreceptor dysfunction and autosomal recessive retinitis pigmentosa. Nature Genetics. 1:209-213.

16. Strosberg, A. D. 1991. Structure/function relationship of proteins belonging to the family of receptors coupled to GTP-binding proteins. Eur. J. Biochem. 196:1-10.

17. Savarese, T. M., and C. M. Fraser. 1992. In vitro mutagenesis and the search for structure-function relationships among $G$ protein-coupled receptors. Biochem. J. 283:1-19.

18. Fraser, C. M., C. D. Wang, D. A. Robinson, J. D. Gosayne, and J. C. Venter. 1989. Site-directed mutagenesis of $\mathrm{m} 1$ muscarinic acetylcholine receptors: conserved aspartic acid residues play important role in receptor function. Mol. Pharmacol. 36:840-847.

19. Strader, C. D., I. S. Sigal, R. B. Register, M. R. Candelore, E. Rands, and R. A. F. Dixon. 1987. Identification of residues required for ligand binding to the $\beta$ adrenergic receptor. Proc. Natl. Acad. Sci. USA. 84:4384-4388.

20. Houslay, M. D. 1992. G-protein linked receptors: a family probed by molecular cloning and mutagenesis procedures. Clin. Endocrinol. 36:525-534.

21. Clark, A. J. L., L. McLoughlin, and A. Grossman. 1993. Familial glucocorticoid deficiency associated with point mutation in the adrenocorticotropin receptor. Lancet. 341:461-462. 